\title{
Chemical diversity of five coastal Roccella species from mainland France, the Scattered Islands, and São Tomé and Príncipe
}

\author{
Solenn Ferron ${ }^{1}$, Olivier Berry ${ }^{1}$, Damien Olivier-Jimenez ${ }^{1}$, Isabelle Rouaud ${ }^{1}$, Joël Boustie ${ }^{1}$, \\ Françoise Lohézic-Le Dévéhat ${ }^{1 *}$ \& Rémy Poncet ${ }^{2 *}$
}

\section{Article info}

Received: 1 Jul. 2020

Revision received: 28 Sept. 2020

Accepted: 13 Oct. 2020

Published: 29 Dec. 2020

\section{Associate Editor}

Alice Gerlach

\begin{abstract}
Roccella species constitute interesting models to address questions regarding lichen metabolite diversity across taxonomic, ecological and geographic gradients. Indeed, owing to their wide distribution, their taxonomic diversity and the narrow ecological niche they occupy, Roccella species are good candidates to study the drivers of lichen chemistry. This study focuses on the chemical profiling of five species: $R$. applanata, $R$. belangeriana, $R$. fuciformis, $R$. montagnei and $R$. phycopsis. These five species were sampled in a rather narrow longitudinal range $\left(1^{\circ} 51^{\prime} \mathrm{W}\right.$ to $\left.47^{\circ} 17^{\prime} \mathrm{E}\right)$ covering the Eastern Atlantic and Western Indian Ocean areas along an extended latitudinal range $\left(48^{\circ} 49^{\prime} \mathrm{N}\right.$ to $\left.22^{\circ} 23^{\prime} \mathrm{S}\right)$. High Pressure Liquid Chromatography (HPLC) analysis followed by mass spectrometry of 31 Roccella thalli revealed a number of interesting patterns through a multivariate (PCA) analysis, including the first detailed chemical profiles for two species from the Scattered Islands: $R$. applanata and $R$. belangeriana. Metabolite segregation amongst all studied Roccella species, including $R$. montagnei and $R$. belangeriana, gave some insight into the taxonomy of the latter two species, which we interpret as separate species. An additional analysis focusing on $R$. montagnei samples revealed chemical differences along both a latitudinal and ecological gradient (from Europa Island to São Tomé and Príncipe). Three mass spectra databases were built to dereplicate the ions, which gave an overview of the factors that could drive quantitative and qualitative metabolite composition in lichens. Additionally, several new Roccella species records are reported for the Scattered Islands, as well as São Tomé and Príncipe.
\end{abstract}

Key words: Roccella applanata, Roccella belangeriana, Roccella fuciformis, Roccella montagnei, Roccella phycopsis, chemical profile

\section{Introduction}

Roccella is a diverse genus of fruticose lichens numbering approximately 30 species [24 according to Tehler et al. (2010); 31 according to Aptroot and Schumm (2011)]. This genus, which is mainly coastal and restricted to tropical, subtropical, Mediterranean and hyper-oceanic localities of temperate areas, has long drawn naturalists' interests as most of its species have large, fruticose thalli (sometimes in abundant populations) and are of economic interest for their tinctorial properties. For these reasons, Roccella was among the first lichen genera to be described (de Lamarck \& de Candolle 1805) and it has

\footnotetext{
${ }^{1}$ Univ Rennes, CNRS, ISCR (Institut des Sciences Chimiques de Rennes) - UMR 6226, F-35000 Rennes, France

2 UMS 2006 PatriNat (OFB - CNRS - MNHN), Muséum national d'Histoire naturelle, Maison Buffon, CP41, 36 rue Geoffroy SaintHilaire 75005 Paris

* Corresponding authors e-mail: francoise.le-devehat@univ-rennes1.fr and remy.poncet@mnhn.fr
}

received continuous attention since then. Multiple studies by Tehler et al. (2004, 2007, 2009a, b, 2010) brought significant advances for assessing the diversity and distribution of the genus, and together with the world-key provided by Aptroot and Schumm (2011) they provide a rather good framework for studies dealing with Roccella. About 54 secondary metabolites have been reported for this genus, belonging to several classes of compounds. One can find depsides such as erythrin, lecanoric acid, lepraric acid (Huneck 1967; Huneck \& Follmann 1967; Aberhart 1969), as well as their sub-units, the monoaromatic phenols, e.g., beta-orcinol, ethyl orsellinate, and montagnetol (Huneck \& Follmann 1968; Aberhart 1969; Parrot et al. 2014; Duong et al. 2017; Duong \& Bui 2018; Mallavadhani \& Sudhakar 2018). Aliphatic acids like roccellic acid (Huneck \& Follmann 1964) and the chromone 6-hydroxymethyleugenitin (Huneck 1972) have also been reported. Depsidones are not as common in 
the genus Roccella; so far they have only been isolated from $R$. hereroensis and $R$. mossamedana (Follman $\&$ Geyer 1986). They have also been reported from the following Roccellaceae genera: Dendrographa, Enterographa, Lecanactis, and Opegrapha. Dibenzofurans are also uncommon; the only one known is schizopeltic acid, reported from $R$. capensis, as well as the genus Schizopelte (Roccellaceae) (Follman \& Geyer 1986; Elix et al. 1992).

Despite the wealth of knowledge amassed for the genus Roccella, gaps in our knowledge remain regarding chemistry, ecology and distribution of the species. This paper aims to fill some of these gaps by providing new records for several species from two tropical, equatorial localities: the Scattered Islands [Indian Ocean, French Southern and Antarctic Lands (TAAF)] and São Tomé and Príncipe (Atlantic Ocean). In addition, complete chemical profiles are provided for five coastal species: Roccella applanata, Roccella belangeriana, Roccella fuciformis, Roccella montagnei and Roccella phycopsis. Special attention is paid here to assessing chemical diversity (both quantitative and qualitative) of these species along the following gradients: species, individuals, territories and ecology.

\section{Materials and methods}

\section{Lichen samples for chemical analysis}

The five Roccella species studied (Fig. 1) were selected among available material in the authors' collection ('JB' for Univ. Rennes and 'RP' for UMS PatriNat) sampled in different locations between 2002 and 2019. A total of 31 specimens were studied.
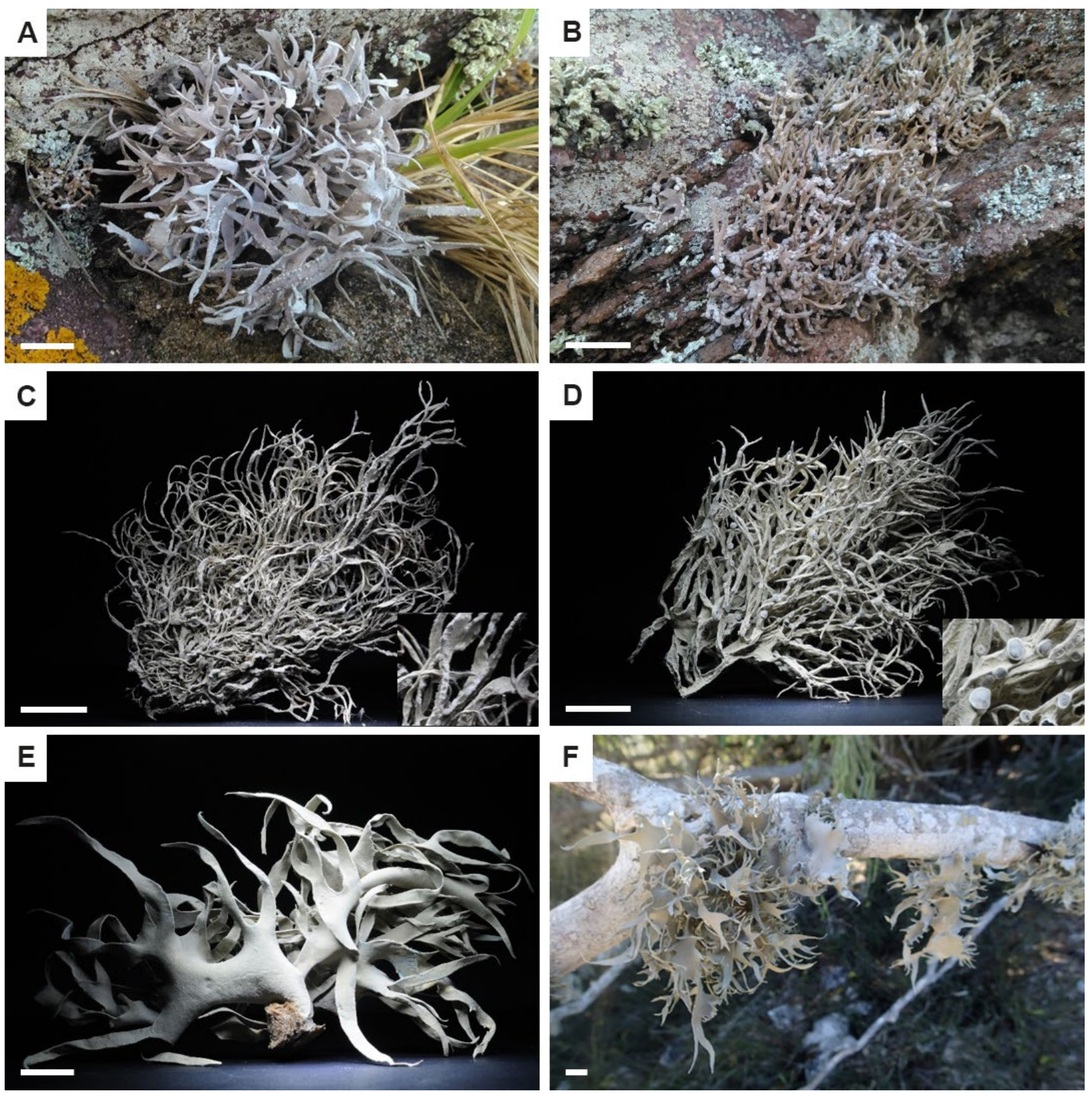

Figure 1. Habit of the five Roccella species studied; A - Roccella fuciformis, France mainland, Bretagne (A.-H. Paradis); B - Roccella phycopsis, France mainland, Bretagne (A.-H. Paradis); C - Roccella montagnei, general view and close-up showing soralia, São Tome and Príncipe ('Sample ID (field)': Poncet, RPO050219 201); D - Roccella belangeriana, general view and close-up showing apothecia, Europa Island, ('Sample ID (field)': Poncet, Europa20190411_13); E-F - Roccella applanata, Europa Island ('Sample ID (field)': Poncet, Europa20190411_4 and Europa20190411_8). 




Figure 2. Map of sampling locations (E - Europa Island, G - Grande Glorieuse, J - Juan de Nova, M/C - Saint-Malo and Cancale, P - Ploumanac'h, S - São Tome and Príncipe).

Figure 2 presents locations where the studied material was collected and Table 1 gives supporting information for all the samples studied in this paper, along with territories where the species were reported for the first time. The French mainland specimens (JB collection) were three samples of $R$. fuciformis collected on granite rocks in Ploumanac'h (22), Saint Malo (Pointe des Chevrets, 35) and Cancale (Pointe du Grouin, 35); and three samples of $R$. phycopsis collected from granite rocks in Saint Malo (Pointe des Chevrets, 35) and in Cancale (Pointe du Grouin, 35). The specimens collected in the Scattered Islands (RP collection) were all collected in 2019 from the bark or wood of several porophytes following a protocol dedicated to assessing the corticolous and lignicolous lichen diversity of these territories (Hivert 2019). The Scattered Islands specimens were three samples of $R$. applanata and six samples of $R$. belangeriana, all from Europa Island; and 16 samples of $R$. montagnei, all from Europa Island, Juan de Nova and Grande Glorieuse. The São Tome and Príncipe specimens (RP collection) were three samples of $R$. montagnei collected on the bark of an unidentified tree species. Altogether, samples from the French mainland represent two of the three Roccella species known from France (Roux et al. 2017). The third species known from France, $R$. tinctoria, is mainly present in Corsica (a mediterranean climate); its presence in Brittany (a hyper-oceanic climate) remains uncertain.
We did not include any samples of $R$. tinctoria in our analyses. Samples from the Scattered Islands represent all Roccella species present on each island (Poncet pers. obs.) and samples from São Tome and Príncipe represent one of the two known species from this territory where R. fuciformis had been recorded by (Nylander 1889); however, we consider this data uncertain owing to its currently known distribution.

\section{Extraction}

Several whole thalli of air-dried lichens (30-100 mg) were cleaned and ground under nitrogen to ensure sufficient pulverization and homogenization which allowed impregnation by the solvents during the extraction process. They were extracted using an extractor device (Heidolph Synthesis) under agitation $(1000 \mathrm{rpm})$ at $35^{\circ} \mathrm{C}$ for 45 minutes with acetone $(2 \mathrm{~mL})$ four times. All filtrates were mixed and evaporated using a Speed Vac Concentrator SPD121P (Thermo Savant) to obtain extracts which were weighed to prepare the sample solutions. Triplicates (or more) were used for each species (Table 1).

High Performance Liquid Chromatography coupled to Mass Spectrometry (HPLC-MS) Analysis

All extracts were dissolved in tetrahydrofuran (THF) at a concentration of $1 \mathrm{mg} \cdot \mathrm{mL}^{-1}$ and filtered $(0.45 \mu \mathrm{m})$ before HPLC injection. 


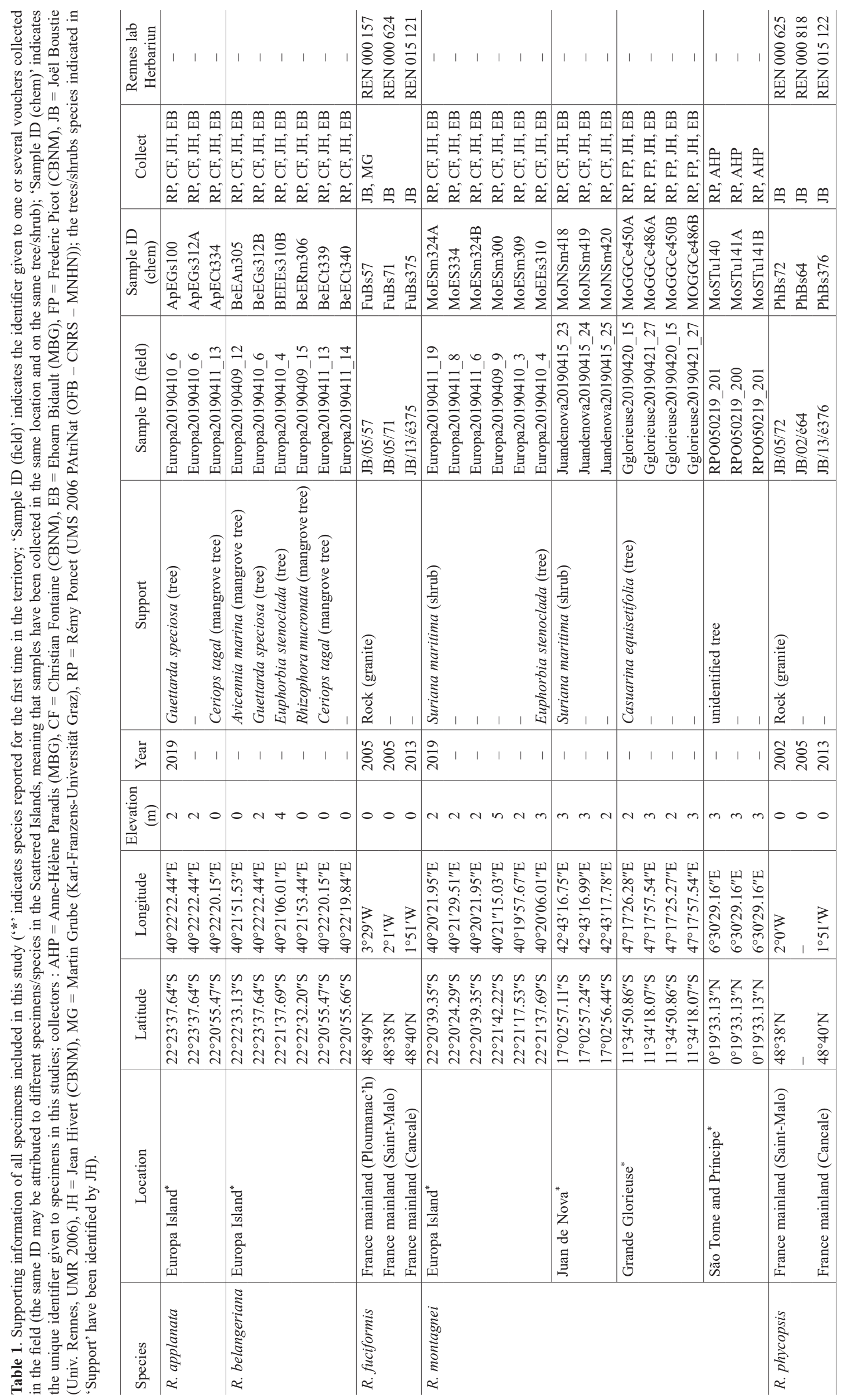


HPLC analysis was carried out using a Prominence Shimadzu LC-20AD system (Marne La Vallée, France). The samples were eluted through a C18-column $(2.6 \mu \mathrm{m}$, $100 \times 4.6 \mathrm{~mm}$, Phenomenex). The mobile phase used $0.1 \%$ formic acid in HPLC-grade water (solvent A) and $0.1 \%$ formic acid in acetonitrile (solvent B). The flow rate was $0.5 \mathrm{ml} / \mathrm{min}$. Gradient elution was employed, commencing at $20 \% \mathrm{~B}$, held for $5 \mathrm{~min}$, increased to $80 \% \mathrm{~B}$ over $25 \mathrm{~min}$, then increased $100 \% \mathrm{~B}$ over $5 \mathrm{~min}$, held for $7 \mathrm{~min}$ before decreasing back to $20 \%$ B held for $3 \mathrm{~min}$. A solvent blank containing solvent only was run for the purpose of subtracting background spectra (Gadea et al. 2018).

Mass spectrometry analysis was carried out using an ADVION expression CMS mass spectrometer. We used an electrospray ionization source over a mass range of $99.85-999.8 \mathrm{~m} / \mathrm{z}$ in negative mode. The ion spray voltage was set at $3.5 \mathrm{kV}$, the capillary voltage at $180 \mathrm{~V}$, the source voltage offset at $20 \mathrm{~V}$, the source voltage span at $20 \mathrm{~V}$, the source gas temperature at $50^{\circ} \mathrm{C}$, and capillary temperature at $250^{\circ} \mathrm{C}$. LC-MS data were acquired using Advion data express software.

\section{Mass Spectral Data processing}

Each MS1 .datx file was exported as *.cdf and mass spectral data were processed using the MZmine 2.52 freeware (http://mzmine.sourceforge.net/) (Pluskal et al. 2010). The mass detection was performed with a noise level set at 2E6. ADAP chromatogram builder (Myers et al. 2017) was run using as parameters a minimal number of scans of 4; group intensity threshold and min highest intensity of $2 \mathrm{E} 6$ and $\mathrm{m} / \mathrm{z}$ tolerance of $0.8 \mathrm{~m} / \mathrm{z}$. Then deconvolution was applied using the ADAP Wavelets algorithm. Dereplication was realized through three personal databases built in the lab. The first one, called HLDB, uses standards injected according to the same chromatographic protocol; identification was done by comparison of their retention time and MS1 data. The second one, called RoccellaDB, was realized through an extensive bibliographic study of the metabolites found in Roccellaceae family coupled with their molecular weight obtained from Huneck Data's (Huneck \& Yoshimura 1996), as well as prediction of their retention time (predicted RT). These predicted RT (text S1) were determined by a linear regression based on their lipophilicity using the online AlogPs software (Tetko 2005). The third one, called LDB-MS1, was a database built by Damien Olivier-Jimenez (in prep.); it contains a large array of lichen metabolites together with their structures, along with their calculated $\mathrm{m} / \mathrm{z}$ (here for $\left.[\mathrm{M}-\mathrm{H}]^{-}\right)$and their predicted RT. All data were exported as .csv files for further multivariate analysis.

\section{Multivariate analysis}

All MZmine files (MZattributes.csv) were uploaded to MetaboAnalyst 4.0 software (https://www.metaboanalyst. ca/MetaboAnalyst) (Chong et al. 2018) for multivariate statistical data analysis. The file comprised a list of features $(\mathrm{m} / \mathrm{z}$, retention times and intensities). Integrity was checked, missing values were replaced by very low values (half of the lowest), and data were filtered using the interquantile range (IQR) to remove variables close to the baseline. All data were normalized using log transform and scaled by the Pareto method (mean-centered and divided by the square root of standard deviation of each variable) (van den Berg et al. 2006).

\section{Results}

\section{Metabolic profiles of the five Roccella species}

The LC-MS profiles of the five species were acquired and the mass chromatograms are provided in Figure 3. Four major compounds were identified according to their retention time and their $\mathrm{m} / \mathrm{z}$ using the HLDB (Fig. 3): the two depsides erythrin $(\mathrm{RT}=15.8 \mathrm{~min} ; \mathrm{m} / \mathrm{z}=421)$ and lecanoric acid $\left(\mathrm{RT}=19.4 \mathrm{~min} ; \mathrm{m} / \mathrm{z}=317\left([\mathrm{M}-\mathrm{H}]^{-}\right.\right.$, molecular peak) and $167\left(\left[\mathrm{M}-\mathrm{C}_{8} \mathrm{H}_{7} \mathrm{O}_{3}\right]^{-}\right.$, base peak)); the aliphatic roccellic acid $(\mathrm{RT}=29.7 \mathrm{~min} ; \mathrm{m} / \mathrm{z}=299)$; and the chromone lepraric acid $(\mathrm{RT}=19.4 \mathrm{~min} ; \mathrm{m} / \mathrm{z}=361$ ([M-H]',molecular peak) and 317 ([M-CHO $]^{-}$, base peak)). The depside lecanoric acid and the chromone lepraric acid have the same RT, and present a similar $\mathrm{m} / \mathrm{z}$ (317), but they are distinguishable by the analysis of complete mass spectrum (Fig. 4). R. fuciformis contains only lepraric acid $\left([\mathrm{M}-\mathrm{H}]^{-}=361.1\right.$; main m/z detected: 317.0 ); whereas $R$. phycopsis, $R$. applanata, $R$. belangeriana and $R$. montagnei only contain lecanoric acid $\left([\mathrm{M}-\mathrm{H}]^{-}=317\right.$; main $\mathrm{m} / \mathrm{z}$ detected: 167.0$)$.

The untargeted and automated processing of these LC-MS data sets, including alignment and clustering of all mass signals into so-called reconstructed chromatograms, resulted in a data matrix of 101 features for all samples analyzed. Finally, in addition to the four main metabolites, seventeen additional compounds were detected. Among them, ten metabolites were annotated with bibliographic support; and for the remaining seven, we found either candidates or a substructure. The depside erythrin was found in all five Roccella species, and lecanoric acid was detected in four species. When lecanoric acid was absent (R. fuciformis), the chromone lepraric acid replaced it. No roccellic acid was detected in $R$. fuciformis and $R$. appla$n a t a$, and the ethyl ether of lepraric acid was only detected in R. fuciformis. All of the putatively annotated compounds are essentially from the monophenolic compounds group. Finally, the possible presence of the butyrolactone roccellaric acid in $R$. montagnei, and the aliphatic acid angardianic acid in $R$. montagnei and $R$. phycopsis can be noted.

\section{Assessment of metabolic segregation between the five Roccella species}

The data matrix obtained after MS data processing was analyzed using statistical analysis. In a first step, an unsupervised multivariate analysis approach (PCA: Principal Component Analysis) was applied to determine differences between samples based on the metabolite presence and the peak intensities. The PCA scores scatter plots of MS1 data showed a separation between species up to $52.5 \%$ of the total variance by the first three principal components (Fig. 5A). 
Base peak intensity

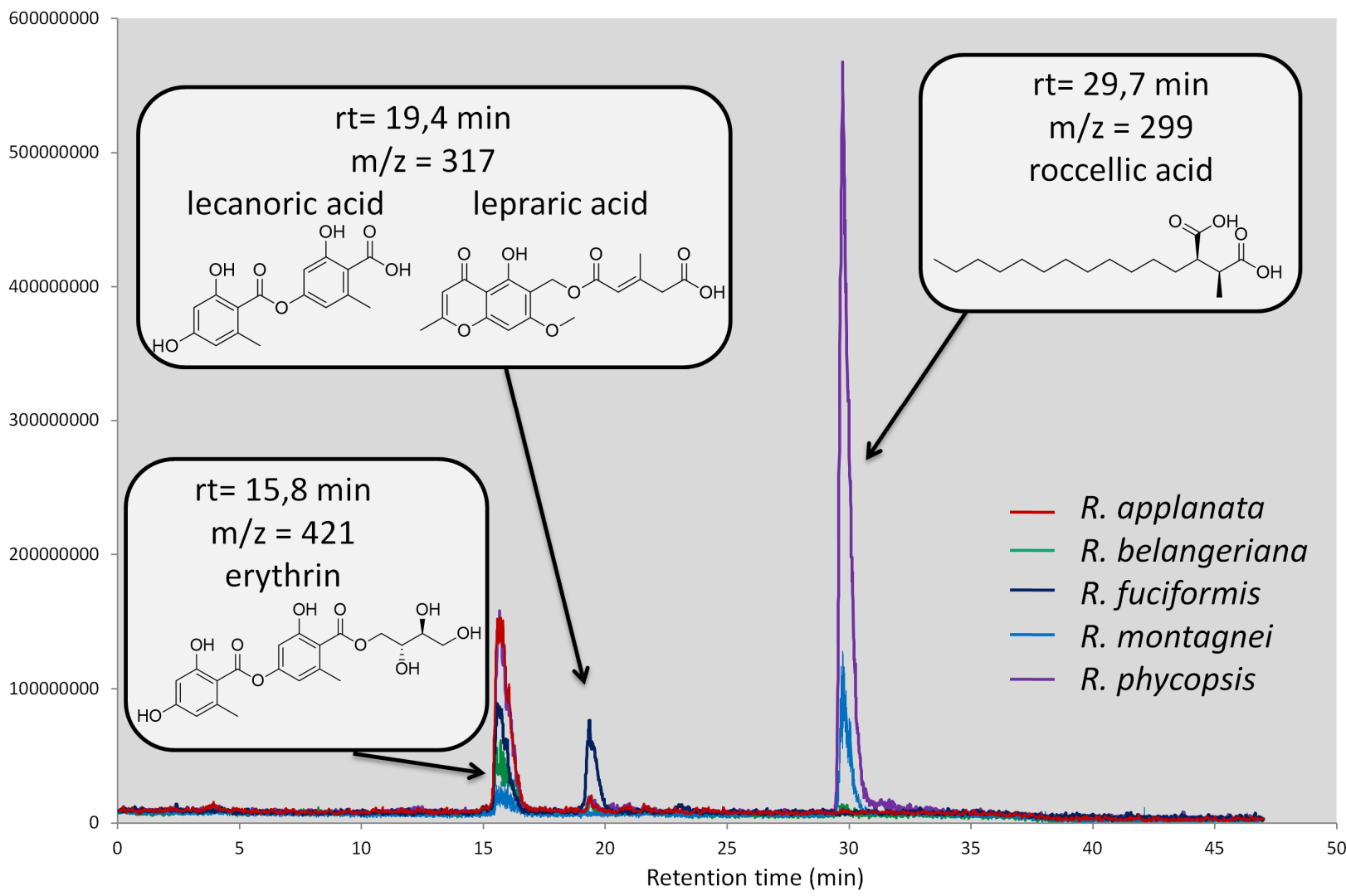

Figure 3. Base peak chromatograms from the HPLC-MS analyses without data processing showing the four major compounds: erythrin, lecanoric, lepraric and roccellic acids. The total ion current (TIC) of the samples of each species were merged in MZmine and the resulting chromatograms were exported into Excel.

Next, the first three components (PC1, PC2 and PC3) were extracted from the $\mathrm{m} / \mathrm{z}$, retention time and intensities of ions under chromatographic conditions. It was demonstrated that there is a clear discrimination between species along the three first components $\mathrm{PC} 1$ to $\mathrm{PC} 3$ (Fig. 5A). $R$. fuciformis specimens constitute a separated outgroup due to the presence of lepraric acid (Table 2), which is clearly visible on PC2. Roccella phycopsis, which is the second species (with R. fuciformis) to grow on rocks in mainland France, forms a compact group located peripherally to an ensemble formed by the three corticolous species $R$. applanata, $R$. belangeriana and $R$. montagnei, which are themselves also rather well-segregated from each other. All of the latter three species are distributed only along a two-dimensional gradient, on the PC1 and PC2 axis.

Then, we used PLS-DA (Supervised Partial Least Squares Discriminant Analysis) (Tenenhaus 1998) to compare the metabolite profiles between samples. The multivariate analyses show clear partitioning in the metabolomic profiles among the five species (Fig. 5B). $R$. applanata, $R$. belangeriana, $R$. montagnei are mainly located along PC1, while PC2 discriminates $R$. phycopsis from $R$. fuciformis, and $\mathrm{PC} 3$ distinguishes $R$. montagnei from $R$. phycopsis. We also notice that $R$. applanata and $R$. fuciformis, the only two species where no roccellic acid was found (Table 2), only segregate according to $\mathrm{PC} 2$.
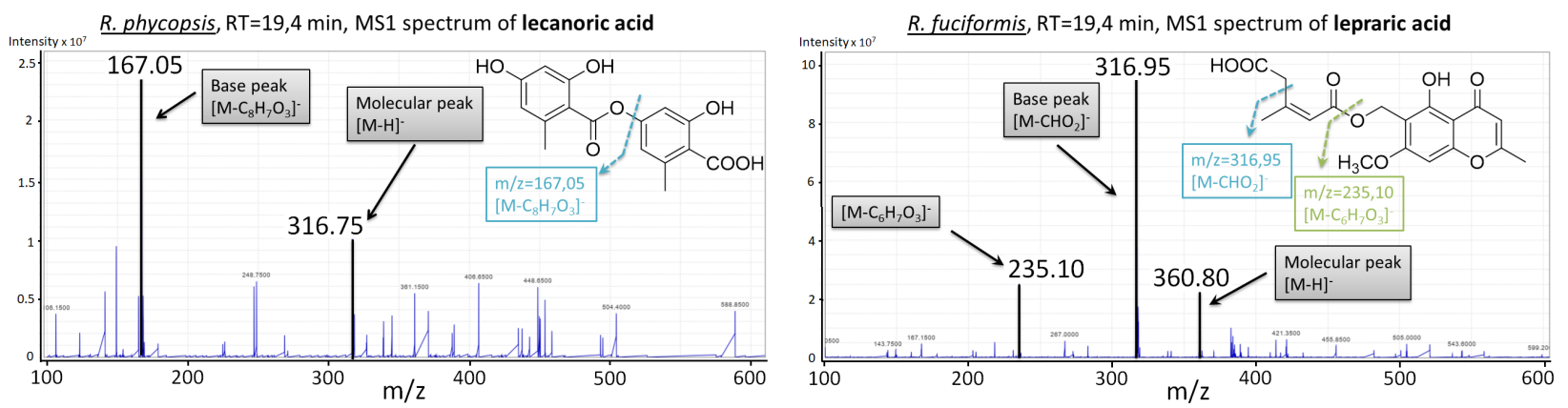

Figure 4. ESI mass spectra (in negative mode) of lecanoric and lepraric acids with their chemical structures. Dash lines show in-source fragmentation of the compounds. 

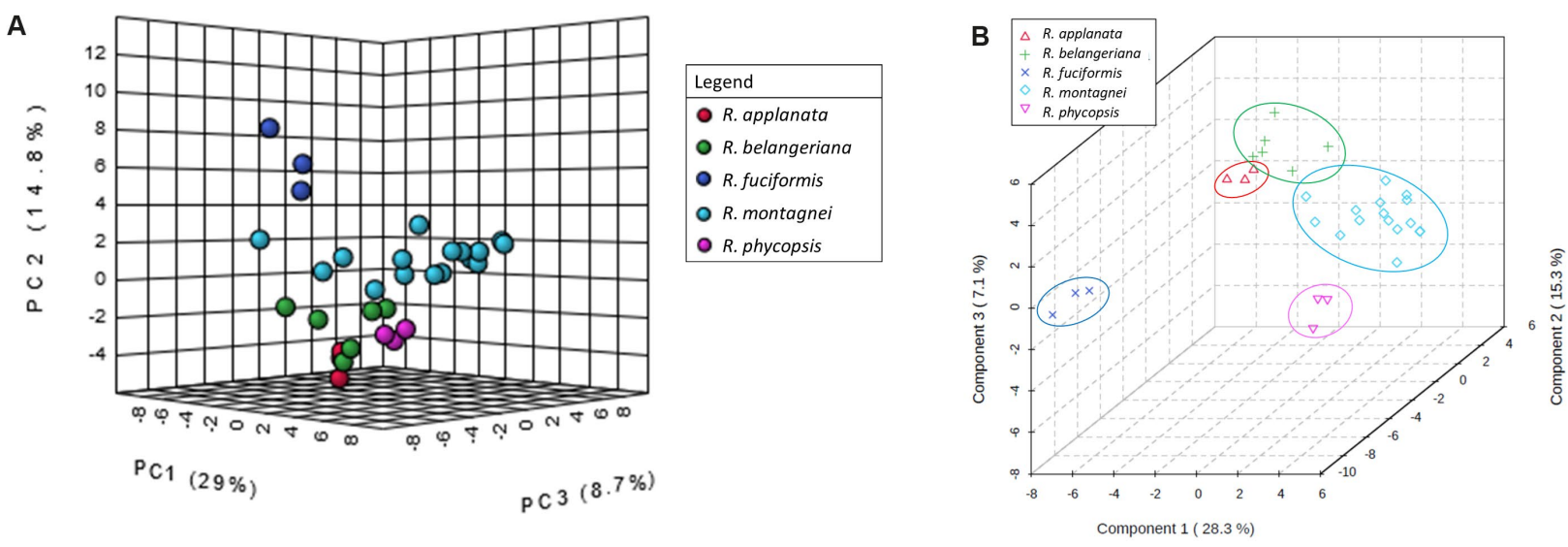

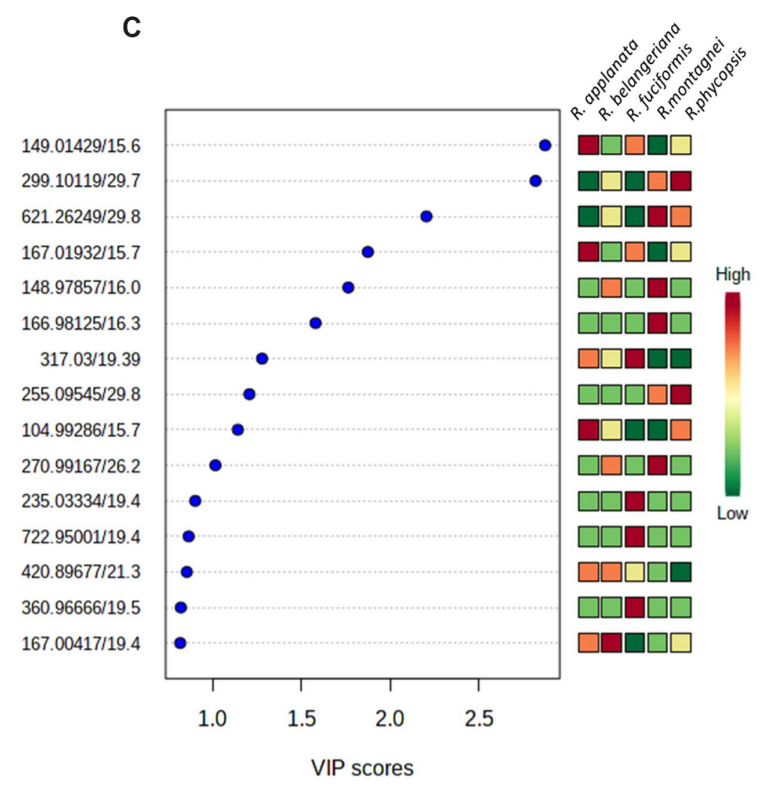

Axes 1-2

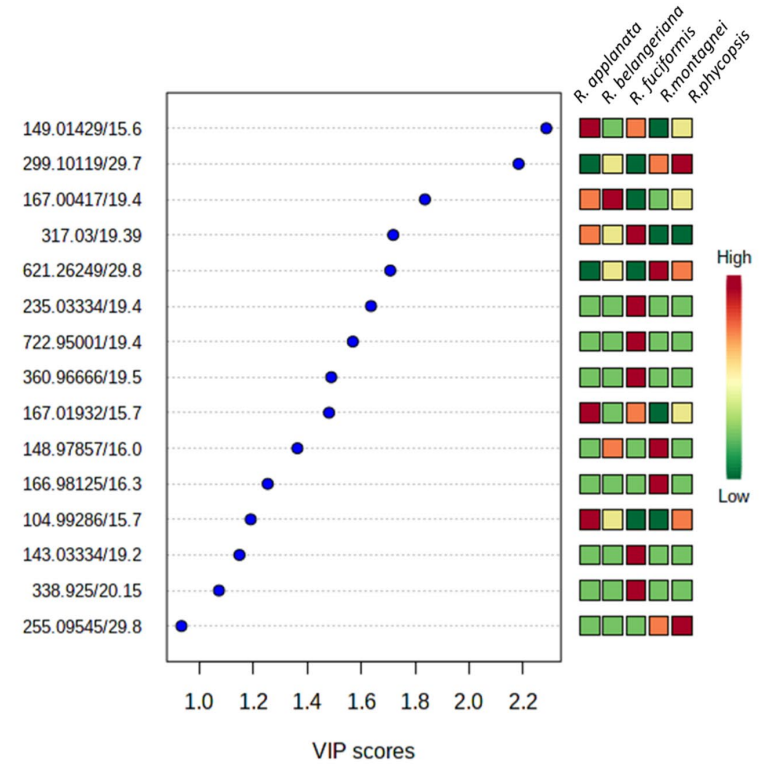

Axes 1-3

Figure 5. A - PCA scores scatter plot of the five species of Roccella (R. applanata, R. belangeriana, R. fuciformis, R. montagnei, and R. phycopsis) showing discrimination between species; B - PLS-DA graphs performed on the metabolites ( $\mathrm{m} / \mathrm{z}$ ) detected in the five Roccella with 3-D scores plotted between selected components; C - Variable Importance in Projection (VIP) identified by PLS-DA. The colored boxes on the right indicate the relative presence of the corresponding metabolite in each group studied.

The main discriminant metabolites $(\mathrm{m} / \mathrm{z})$ are reported on Figure 5C using the measure of the variable's importance in PLS-DA model (VIP score), the highest VIP scores, the most contributive variable is in class discrimination. Roccellic acid was the most discriminant metabolite for R. phycopsis; erythrin, roccellic acid and montagnetol/roccellatol derivative were important for distinguishing $R$. montagnei; and lecanoric acid and lepraric acid were important metabolites for segregating $R$. fuciformis. By contrast, $R$. belangeriana was distinguished by the presence of lecanoric acid, and $R$. applanata by the presence of erythrin together with roccellic acid.

\section{Focus on the $R$. montagnei-belangeriana complex}

The phylogenetically close species $R$. montagnei and $R$. belangeriana (Tehler 2007; Prashanth 2008) were further studied. Using the HPLC-MS data of both species, a PCA analysis was performed for dimension reduction of multivariate data whilst preserving most of the variance for both species. It revealed two clusters representing
$55.1 \%$ of the total variance (Fig. 6A). The PLS-DA was then applied, highlighting significant differences between $R$. montagnei and $R$. belangeriana (Fig. 6B). The variable importance in projection (VIP scores) indicated roccellic acid and erythrin as discriminant metabolites for $R$. montagnei, while lecanoric acid and erythrin were discriminant metabolites for $R$. belangeriana (Fig. 6C) (VIP $>1$ ). All of these metabolites were detected in thalli (Table 2) of both species, but with different intensities.

\section{Metabolite variation in $R$. montagnei at different latitudes}

Metabolites data restricted to Roccella species of this study comprising four tropical territories (Europa Island, Juan de Nova, Grande Glorieuse and São Tome and Príncipe), under comparable ecological conditions (i.e., corticolous at sea level), was used to investigate if the geographical location (or latitude gradient) has an influence on the Roccella metabolome. The mass data processing was based on the ionization of each metabolite and, in 
Table 2. Chemical profiling by HPLC-MS of the five Roccella species studied (R. app: $R$. applanata; R. bel: $R$ belangeriana; R. fuc: $R$ fuciformis, $\mathrm{R}$ mon: $R$. montagnei; R. phy : $R$ phycopsis). Metabolites were identified by their retention time (RT), but also by their molecular mass in negative mode ESI with a major ion corresponding to $[\mathrm{M}-\mathrm{H}]^{-}$and the fragments (reported $\mathrm{m} / \mathrm{z}$ ). The families to which each compound belongs are noted. Compounds in black and bold are dereplicatated identities against HLBD; in grey and bold are putative identities determined by dereplication against RoccellaDB; and in grey and italics against LDB-MS1. Key to symbols: -, absence of metabolites; +, presence of metabolites; nd, not determined.

\begin{tabular}{|c|c|c|c|c|c|c|c|c|c|}
\hline Identified or putative compound & Classification & {$[\mathrm{M}-\mathrm{H}]^{-}$} & $\begin{array}{l}\text { Main ions detected } \\
\qquad(\mathrm{m} / \mathrm{z})\end{array}$ & RT (min) & $\begin{array}{l}\dot{\hat{\Xi}} \\
\dot{\tilde{z}} \\
\dot{1}\end{array}$ & $\begin{array}{l}\dot{\Phi} \\
\dot{0}\end{array}$ & $\begin{array}{l}\dot{己} \\
\dot{\sim}\end{array}$ & $\begin{array}{l}\dot{0} \\
\stackrel{\Xi}{ } \\
\check{1}\end{array}$ & $\frac{\grave{2}}{\dot{2}}$ \\
\hline orsellinic acid & $\begin{array}{l}\text { monophenolic } \\
\text { compounds }\end{array}$ & 167.1 & $167.3 ; 123$ & 6.2 & + & + & - & - & - \\
\hline erythrin & depsides & 420.9 & $\begin{array}{l}420.9 ; 843.1 ; 571.0 \\
534.8 ; 271.0 ; 167.0 \\
149.0 ; 122.9 ; 104.9\end{array}$ & 15.8 & + & + & + & + & + \\
\hline lecanoric acid & depsides & 317 & $317.0 ; 167.1 ; 149.0$ & 19.4 & + & + & - & + & + \\
\hline lepraric acid & chromones & 361 & $\begin{array}{l}760.5 ; 723.0 ; 504.8 \\
382.9 ; 361.2 ; 339.2 \\
317.1 ; 143.0\end{array}$ & 19.5 & - & - & + & - & - \\
\hline roccellic acid & aliphatic acids & 299.1 & $299.1 ; 255.1 ; 621.3$ & 29.7 & - & + & - & + & + \\
\hline montagnetol & $\begin{array}{l}\text { monophenolic } \\
\text { compounds }\end{array}$ & 271.1 (nd) & $167.0 ; 149.0$ & 3.9 & + & + & + & + & + \\
\hline acetylerythritol & polyols & 163.1 & 163.1 & 10.9 & - & - & - & - & + \\
\hline roccellatol & $\begin{array}{l}\text { monophenolic } \\
\text { compounds }\end{array}$ & 271.0 & 271.0 & 12.0 & - & + & - & - & - \\
\hline 2,4-dihydroxyphthalide & $\begin{array}{l}\text { monophenolic } \\
\text { compounds }\end{array}$ & 165.0 & 165.0 & 12.3 & - & - & - & - & + \\
\hline lepraric acid ethylether & chromones & 388.9 & 388.9 & 20.8 & - & - & + & - & - \\
\hline $\begin{array}{l}\text { orsellinylmontagnetol A or } \\
\text { orsellinylmontagnetol B or } \\
\text { orsellinylmontagnetol C }\end{array}$ & $\begin{array}{l}\text { polyphenolic } \\
\text { compounds }\end{array}$ & 420.9 & 420.9 & 21.4 & + & + & - & + & - \\
\hline orsellinylmontagnetol D & $\begin{array}{l}\text { polyphenolic } \\
\text { compounds }\end{array}$ & 570.9 & $570.9 ; 420.9$ & 21.7 & - & + & - & + & - \\
\hline $\begin{array}{l}\text { orsellinylmontagnetol A or } \\
\text { orsellinylmontagnetol B or } \\
\text { orsellinylmontagnetol C }\end{array}$ & $\begin{array}{l}\text { polyphenolic } \\
\text { compounds }\end{array}$ & 420.9 & 420.9 & 22.0 & - & + & - & - & - \\
\hline roccellaric acid & paraconic acids & 325.0 & 325.0 & 31.7 & - & - & - & + & - \\
\hline angardianic acid & aliphatic acids & 327.2 & 327.2 & 33.2 & - & - & - & + & + \\
\hline $\begin{array}{l}\text { 8-methoxytrypethelone methylether or } \\
\text { bis-(2,4-dihydroxy-6-n-propylphenyl)-methane } \\
\text { or pannaric acid }\end{array}$ & nd & 315.0 & 315.0 & 20.4 & - & - & - & + & + \\
\hline 6,8 -di- $O$-methylnidurufin or pyrenulicacid $\mathrm{G}$ & nd & 411.0 & 411.0 & 24.0 & + & - & - & - & - \\
\hline isidiophorin or siphulin & nd & 425.2 & 425.2 & 25.5 & + & - & - & - & - \\
\hline montagnetol or roccellatol derivative & $\begin{array}{l}\text { monophenolic } \\
\text { compounds }\end{array}$ & 271.0 & 271.0 & 26.2 & - & - & - & + & - \\
\hline orcinyllecanorate & depsides & 422.6 & 422.6 & 31.2 & - & - & - & - & + \\
\hline cholesta-3,5-dien-7-one & terpene & 381.9 & 381.9 & 45.2 & - & + & - & - & - \\
\hline oleic acid & aliphatic acids & 280.8 & 280.8 & 45.3 & - & + & - & - & - \\
\hline
\end{tabular}

Abbreviations: R. app: R. applanata; R. bel: $R$ belangeriana; R. fuc: $R$ fuciformis, R. mon: R. montagnei; R. phy: $R$ phycopsis

a first step for each ion, we calculated the ratio of each area intensity to build Figure 7.

Among the compounds identified from HLDB and from the RoccellaDB, the three metabolites erythrin, roccellic acid and orsellinylmontagnetol A (or $\mathrm{O}$. B, or O. C) are present in rather similar proportions in the lichen thalli from the four locations (Fig. 7). Among the 7 other metabolites identified, two were present in only one location: angardianic acid (Europa Island) and roccellaric acid (Grande Glorieuse), three were present in two locations: montagnetol or roccellatol derivative and lecanoric acid (Europa Island and Grande Glorieuse), orsellinylmontagnetol D (Europa Island and São Tome and Príncipe), and two were present in three locations. In addition, $R$. montagnei specimens growing in Europa Island contain the largest diversity of metabolites $(8 / 10)$, followed by those from Grande Glorieuse (7/10), from São Tome and Príncipe (6/10) and from Juan de Nova (5/10).

In a second step, we performed a multivariate PCA analysis (Fig. 8A), followed by a supervised PLS-DA (Fig. 8B). Although the R2 and Q2 values for PLS-DA were quite low, it appears that specimens found in Europa Island differed from those from São Tome and Príncipe along the $\mathrm{PC} 1$ axis (22.7\%). PC3 axis allows discrimination between the specimens collected in Grande Glorieuse and the others. The compounds that contributed the most 

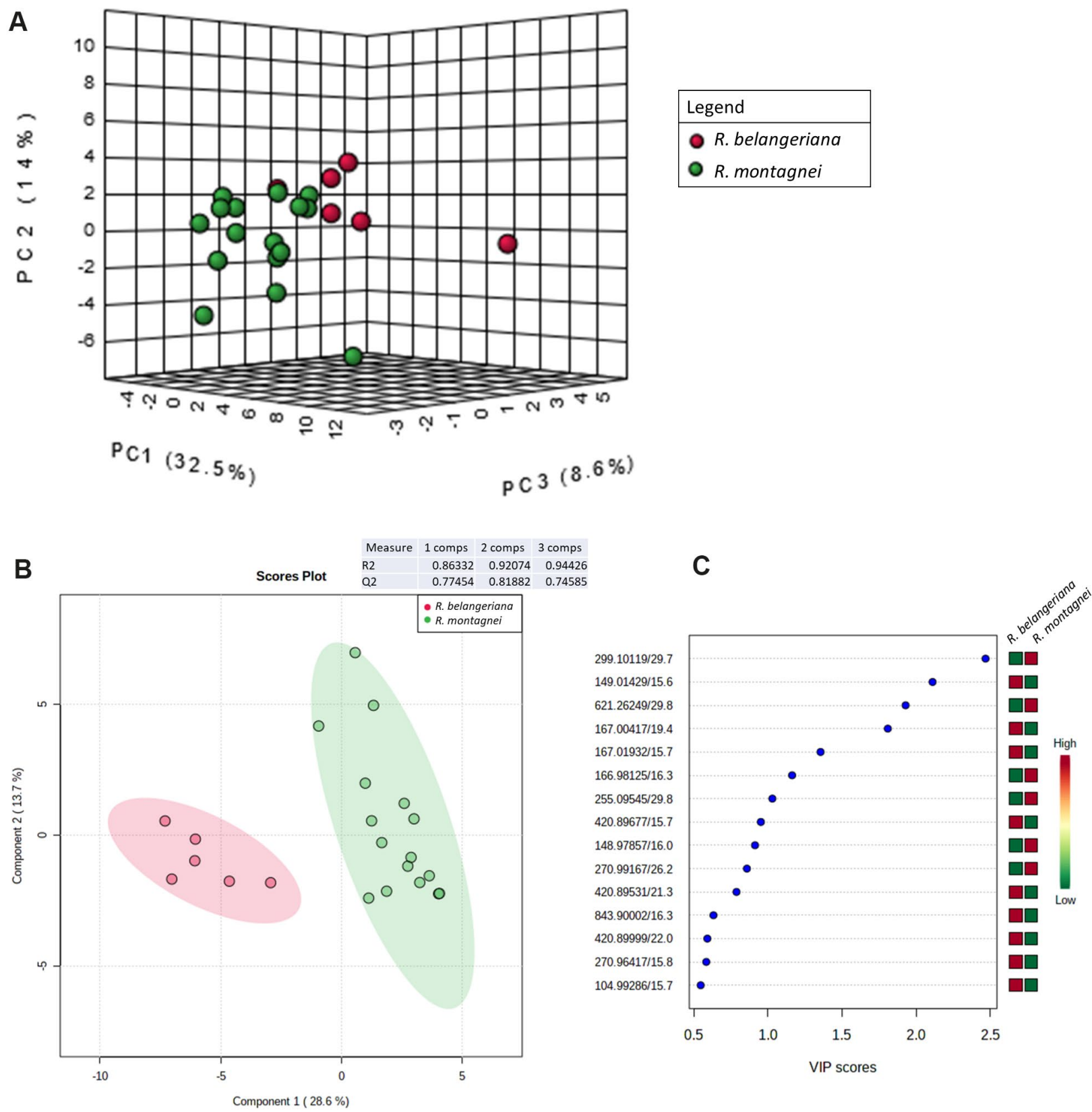

Figure 6. A - APCA scores scatter plot of $R$. belangeriana and $R$. montagnei showing discrimination between the species; B - 3-D scores plot of PLS-DA between selected components performed on the metabolites $(\mathrm{m} / \mathrm{z})$ detected in $R$. montagnei and $R$. belangeriana; $\mathrm{C}-\mathrm{Variable}$ Importance in Projection (VIP) identified by PLS-DA. The colored boxes on the right indicate the relative presence of the corresponding metabolite in each group studied.

(VIP $>1)$ to discrimination were montagnetol/roccellatol derivative, erythrin and roccellic acid for thalli collected in Europa Island; erythrin for $R$. montagnei collected in Juan de Nova; and montagnetol and orsellinyl montagnetol for specimens collected in Sao Tomé (Fig. 8C).

\section{Discussion}

\section{Improved knowledge of Roccella chemistry}

The establishment of metabolic profiles of the five Roccella species included in this study (Table 2) improves our knowledge of these species' chemistry and according to the data contained in RoccellaDB (our bibliographic database focused on metabolites found in Roccellaceae), five compounds were detected for the first time in this genus: 2,4-dihydroxyphthalide (R. phycopsis; French mainland); orcinyl lecanorate (R. phycopsis; French mainland); roccellaric acid ( $R$. montagnei; Grande Glorieuse); cholesta-3,5-dien-7-one ( $R$. belangeriana; Europa Island); and oleic acid ( $R$. belangeriana; Europa Island). Moreover, the chemistry of $R$. applanata (Europa Island) was profiled for the first time, resulting in the identification of three compounds (all monophenolic compounds or depsides), plus four requiring further investigation (all probably polyphenolic compounds). $R$. belangeriana (Europa Island) was also profiled for the first time, resulting in the dereplication of seven compounds (all monophenolic compounds, depsides, aliphatic acids, polyphenolic compounds or terpenes), plus two polyphenols requiring further investigation and two apolar putative compounds (oleic acid and 


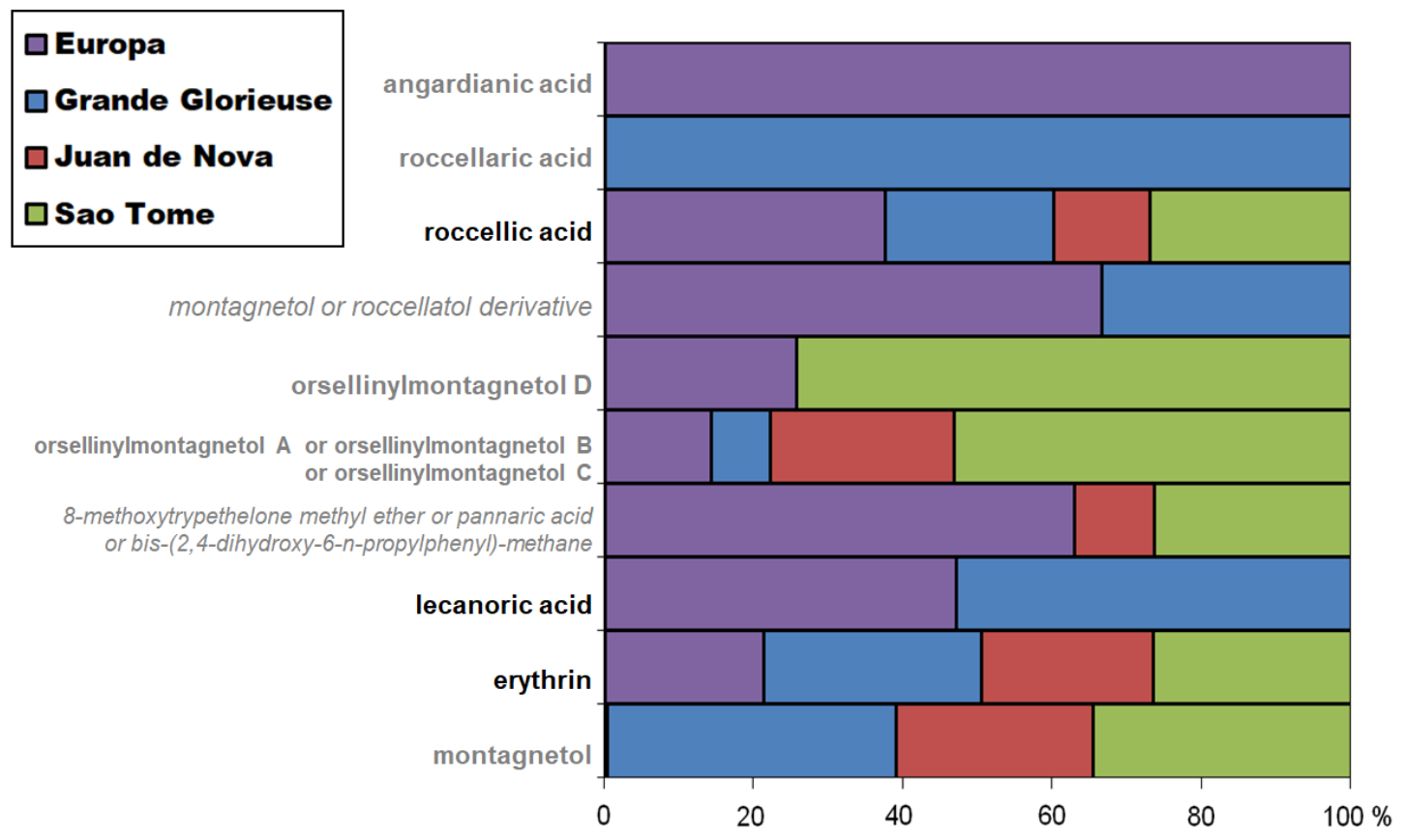

Figure 7. Ratio of the metabolites (in \% of ion intensity) calculated in the samples of $R$. montagnei collected in Europa Island, Juan de Nova, Grande Glorieuse and Sao Tomé. The identification of the metabolites was realized using the HLDB (in bold) and RoccellaDB/LDB-MS1 databases and was based on the molecular mass in negative mode ESI (reported m/z), as well as their retention time (RT). The data are from HLDB (bold and black), roccellaDB (bold and grey), and LDB-MS1 (italic and grey).

cholesta-3,5-dien-7-one). Additionally, two compounds were dereplicated for the first time in $R$. montagnei: roccellaric acid (butyrolactone) and angardianic acid (aliphatic acid), plus two requiring further investigation, and three compounds in $R$. phycopsis: acetylerythritol (polyol), 2,4-dihydroxyphthalide (monophenolic compound), orcinyl lecanorate (depside), plus one requiring further investigation. In total, these analyses performed under the same conditions with all specimens allowed us to assess metabolite variation between species with a maximum diversity of compounds reached by $R$. belangeriana $(\mathrm{n}=11)$, followed by $R$. montagnei $(\mathrm{n}=10), R$. phycopsis $(\mathrm{n}=9), R$. applanata $(\mathrm{n}=8)$ and $R$. fuciformis $(\mathrm{n}=4)$. It is possible that if our sample sizes were increased for each species, further chemical diversity would have been discovered. Interestingly, our analyses - performed on just a fraction of the total known Roccella species - seems to indicate that metabolite richness is higher in corticolous species than in saxicolous ones; however, these results are tentative, and further investigation is necessary to make more robust conclusions. Another interesting result is that there seems to be no correlation between the extension of species distribution area and compound richness. Indeed, $R$. montagnei, $R$. phycopsis and $R$. fuciformis are widespread species, whereas $R$. applanata is an endemic species from Madagascar and Europa Island.

The depside erythrin was found in the five Roccella species, and this aromatic compound was reported in 18 taxa of Roccella out the 54 (infra-specific taxa included) (Huneck 1967; Huneck \& Follmann 1967, 1968; Strack et al. 1979; Thadhani et al. 2012; Parrot et al. 2014; Duong et al. 2017; Sweidan et al. 2017; Brakni et al. 2018). It appears that either this compound is present in Roccella species; or, another depside, lecanoric acid, is present. Only four species have been reported possessing both depsides: $R$. phycopsis, $R$. linearis (var. guineensis and var. hypochromatica) and R. montagnei from Asia and Africa (Huneck \& Follmann 1968). The chromone lepraric acid was only found in R. fuciformis; it appears to be diagnostic for this species (Aberhart 1969). Surprisingly, acetylportentol, previously described as a major compound in R. fuciformis (Parrot et al. 2014; Sweidan et al. 2017), was not found here. However this aliphatic compound is not expected to be detected under UV, and appears to be hardly ionized. Therefore, we analyzed the extracts of R. fuciformis with HPLC-MS using an universal Evaporation Light Scattering Detector (ELSD) and confirmed the presence of a peak at RT $=23.30$ min corresponding to acetylportentol (data not shown). Nevertheless, $R$. fuciformis can be easily identified by its other metabolites, such as lecanoric and lepraric acids. Moreover, given the high intensities of the peaks for the main compounds, it was difficult to detect picrorocellin (Marcuccio \& Elix 1983) and 6-hydroxy-methyleugenitin in R. fuciformis (Huneck 1972).

Three acids were detected or suspected: roccellic acid was detected in $R$. belangeriana (two specimens out of 6: BeEEs310B and BeECt339), R. montagnei (all specimens) and $R$. phycopsis (all specimens); angardianic acid was suggested for $R$. phycopsis (two out of three specimens: PhBs64, PhBs72) and three specimens out of 16 of R. montagnei (three specimens out of 16: MoESm324B, MoEEs310, MoESm334); and roccellaric acid was suspected in one specimen of $R$. montagnei (MoGGCe450A). As seen in Figure S3, roccellic acid differs from angardianic acid by the length of the side chain with 12 vs. 14 carbons, respectively. Roccellaric acid has a side chain with thirteen carbons, but results from the cyclization of the angardianic acid. Thus, it is necessary for the lichen 

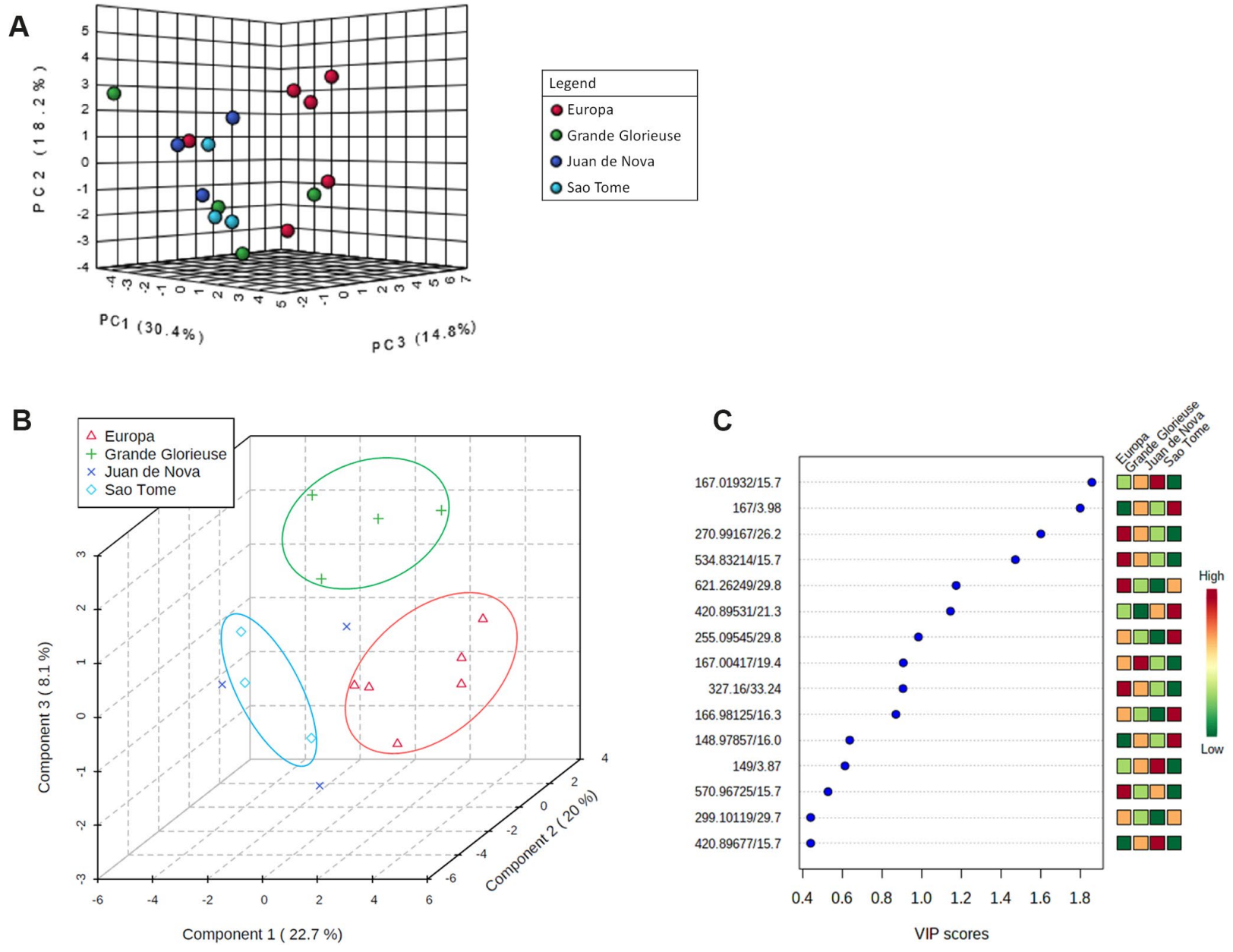

Figure 8. A - PCA scores scatter plot of R. montagnei collected in Europa Island, Juan de Nova, Grande Glorieuse and Sao Tomé; B - 3D PLS-DA scores scatter plot of the different samples of $R$. montagnei collected at the four locations; C - Variable Importance in Projection (VIP) identified by PLS-DA. The colored boxes on the right indicate the relative concentrations of the corresponding metabolite in each group studied.

to have sufficient energy to produce longer chains, and also to activate enzymes like deshydratases to form the paraconic acid, roccellaric acid. This could explain why roccelic acid seems more prevalent in the Roccella species (e.g., R. montagnei) that also produces angardianic and roccellaric acids.

\section{R. montagnei-belangeriana complex}

The studied dataset showed that a clear segregation occurs in metabolite composition between specimens considered in this publication as $R$. montagnei (thallus $\mathrm{C}+$ red, generally sterile, with soralia, rarely with apothecia) and $R$. belangeriana (thallus $\mathrm{C}+\mathrm{red}$, fertile, without soralia). These two taxa are considered as synonyms by Tehler et al. (2010), although they could not integrate the holotype into their phylogenetic analysis of Roccella species from the Paleotropics (because they were unable to receive the holotype on loan). Prashanth et al. (2008) also asserted that $R$. montagnei and $R$. belangeriana are the same species, basing their conclusion on the analysis of ITS sequences and indicating that these two taxa are similar in both morphology and secondary chemistry. The results obtained here tend to reinforce the existence of at least two taxa in the $R$. montagnei-belangeriana complex. First, Table 2 and Figures 6A and 6B show that the species
$R$. belangeriana and $R$. montagnei differed statistically by their monophenolic compounds (orsellinic acid roccellatol, orsellinylmontagnetol, montagnetol/roccelatol derivative), as well as by their aliphatic acids (roccellaric and angardianic acids). Nevertheless, the statistical analyses also suggest that roccellic acid, erythrin and lecanoric acid are the only reliable discriminant metabolites, even though these three compounds are present in both species (Fig. 6C). This can be explained by the difference in intensities of these major compounds: when a metabolite is concentrated, some charged dimers and monophenolic compounds are generated in the mass spectrometer. Because of this, all these ions are analyzed and are thus taken into account for the multivariate analysis. Moreover, as we can see in Figure S2 (supporting info), all the monophenols are units of erythrin, which is itself an ester of erythritol with lecanoric acid. In addition, their uneven distribution across the Scattered Islands ( $R$. montagnei and $R$. belangeriana are both present in Europa Island, but $R$. montagnei is the only Roccella found in Juan de Nova and Grande Glorieuse) suggests that their dispersal strategy (or perhaps some difference in their ecological niches) do not allow them to colonize as efficiently in these rather close territories (Fig. 2). This difference in their distribution suggests the existence of at least two 
ecotypes, or two species, among which one has the ability to abundantly produce apothecia, when the other only uses an asexual dispersion strategy (apothecia can rarely be found, but even so, the thalli remain sorediate). Finally, based on our limited sample sizes for both species, it appears that the two have rather distinct ecological niches ( $R$. belangeriana occurs more often on mangrove trees), even if they sometimes were found together on the same tree with significantly bigger thalli of $R$. belangeriana (wider branches) compared to $R$. montagnei. So, combined with these observations, the distinct metabolite profiles of these two taxa is an incentive for further phylogenetic analysis based on several loci and on additional material from the Roccella montagnei-belangeriana complex.

\section{Metabolites profiling across location of $R$. montagnei}

The results showed that the only Roccella species common in Europa Island, Juan de Nova, Grande Glorieuse, São Tomé and Príncipe display metabolic differences, both qualitatively and quantitatively (Fig. 8A-C). However, we can note that PCA did not show clear segregation between locations, as clearly shown in the PLS-DA scatter plot (Fig. 8B). Erythrin was the only diagnostic compound for the $S$. montagnei samples collected in Juan de Nova, while monophenolic compounds (montagnetol, orsellinylmontagnetol) differentiated thalli growing in São Tomé and Príncipe. Thalli collected in Europa Island contain roccellic acid in addition to montagnetol/roccellatol derivatives and erythrin; however, six of the $16 R$. montagnei thalli were collected in Europa Island, and this higher chemical diversity could be a result of greater sample size. As stated previously, erythrin is the final step of the proposed biosynthetic pathway resulting from two esterification reactions: the first, between monophenolic units; and the second, the joining of the depside lecanoric acid with the polyol erythritol (Culberson 1969) (Fig. S3). A possible explanation of variations of this metabolite between sampling locations could be variation in exposure of the thalli to solar radiation (UV). Indeed, thalli growing in Europa Island and Juan de Nova were often collected in less sheltered conditions on the shrub Suriana maritima, while those from Grande Glorieuse were collected on the tree Casuarina equisetifola where they probably benefited from the shade of its canopy. The same can be said for those collected in São Tomé and Príncipe, which were growing on the trunks and branches of an unidentified tree, and thus protected from the sun. In other words, an interesting gradient is seen between specimens growing in a tropical climate. Specifically, material collected from Europa Island and Juan de Nova with supposed UV-exposed conditions produce large quantities of erythrin, while specimens collected from Grande Glorieuse in rather sheltered locations produce a mixture of erythrin and monophenolic compounds. The latter are also the dominant compounds in specimens collected from São Tomé and Príncipe, which are also more sheltered from UV exposure. For the two studied species growing in the Northern hemisphere and generally found in sheltered rocks, the diagnostic compounds for $R$. fuciformis were the two depsides lecanoric and lepraric acids, while the diagnostic compound for $R$. phycopsis was the aliphatic acid roccellic acid. Future studies could incorporate complementary molecular analyses to help address whether these chemical variations among thalli are either inherited or acquired due to environmental conditions. However, no ecological variables (e.g., amount of solar radiation) were measured as part of this study, thus these proposed explanations are conjectural and further data measurements of UV radiation are needed to address their reliability.

\section{Conclusion}

The following six compounds were found in large amounts in the five Roccella species studied: erythrin, lecanoric acid, lepraric acid, orsellinyl montagnetol, montagnetol and roccellic acid. Of these five species, the chemistry of $R$. applanata and $R$. belangeriana were studied in detail for the first time. Distinct chemical profiles support segregation of all of these species regardless of their ecological or geographic similarity or phylogenetic relationship. Analyses of the chemical profiles of $R$. montagnei and $R$. belangeriana - together with other anecotal observations related to distribution and ecology - give additional support to distinguish them as separate species. Molecular phylogenetic analyses involving duplicates of the material analyzed, here along with additional material from the $R$. montagnei-belangeriana complex, would be helpful to better circumscribe species in this complex. Finally, a comparison of the profiles and relative amounts of metabolites between the sub-tropical Roccella species (from Europa Island, Juan de Nova, Grande Glorieuse, São Tomé and Príncipe) suggests an effect of sun exposure on chemical composition of these lichens. Our results indicate that species explains the majority of chemical diversity seen amongst the species studied here, with slight modifications driven by ecological factors such as substrate (corticolous species seem chemically richer than saxicolous ones) and sun-exposure (specimens from more sheltered conditions being more chemically diverse).

\section{Acknowledgements}

Aurélie Bernard (ISCR) is acknowledged for her technical assistance. The authors warmly thank Rémy Ferron for his help in the set-up of the retention time prediction model used for the RoccellaDB and LDB-MS1 databases. We are also grateful to Léonie Gourdon who initiated the data analysis. RP gives special thanks to Sylvie Chevalier (UMS 2006 PatriNat), Mélanie Hubert (UMS 2006 PatriNat), Laurent Poncet (UMS 2006 PatriNat), Julien Touroult (UMS 2006 PatriNat) and Serge Muller (ISYEB - MNHN) for their trust and mostly for their invaluable help in this project, and without whom none of this would have been possible. Sophie Marinesque (TAAF), Jonathan Grand (TAAF) and Cedric Marteau (TAAF) who coordinated the consortium and the field campaigns, and invested countless energy and time for improving the Scattered Islands' natural heritage knowledge and conservation, are also warmly thanked. Finally, friendly thanks go also to Jean Hivert (CBNM) for his help in designing the field sampling and identification of trees/shrubs in the Scattered Islands; and to Christian Fontaine 
(CBNM), Frédéric Picot (CBNM), Ehoarn Bidault (MBG) and Anne-Hélène Paradis (MBG) for their invaluable help in the sampling and foraging of lichens species in the Scattered Islands (JH, CF, FP, EB) and in Sao Tomé (AHP). We are grateful to $\mathrm{S}$. LaGreca for his useful comments which greatly improved the manuscript.

\section{Funding}

Some species studied in this paper were collected in the frame of the 'Scattered Island' inter-agency research consortium (20172021) coordinated by the French Southern and Antarctic Lands (TAAF) in partnership with: Centre National de la Recherche Scientifique, Institut de Recherche pour le Développement, Ifremer, Agence Française pour la Biodiversité, Université de La Réunion \& Université de Mayotte. Fieldwork was funded by the inter-agency research consortium and was done jointly by the Conservatoire Botanique National de Mascarin, the Missouri Botanical Garden and the Muséum National d'Histoire Naturelle (UMS 2006 PatriNat OFB - CNRS - MNHN) in the frame of the RECOFFIE (Renforcement des COnnaissances sur la Flore et la Fonge des Iles Éparses) project, implemented as part of the 'Scattered Island' inter-agency research consortium (2017-2021)

\section{Permits}

Collecting of the lichen species were authorized in the Scattered Islands according to the permit delivered by C. Geoffroy, General Secretary of French Southern and Antarctic Lands and district head of the Scattered Island. The RECOFFIE (CBNCPIE Mascarin, MBG, UMS 2006 PatriNat (OFB - CNRS MNHN)) project was authorized by order $n^{\circ} 2019-40$ of April 1, 2019. Collecting of the lichen species was authorized in São Tomé and Príncipe according to the permit 003/2019 delivered by CIAT-STP (Ministério de Agricultura, Pesca e Desenvolvimento Rural) in February 2019.

\section{Competing interests}

The authors declare that they have no financial or personal relationships that may have inappropriately influenced them in writing this article.

\section{References}

Aberhart, D. J., Overton, K. H. \& Huneck, S. 1969. Studies on lichen substances. Part LX1I.1 Aromatic constituents of the lichen Roccella fuciformis DC. A revised structure for lepraric acid. Journal of the Chemical Society 5: 704-707.

Aptroot, A. \& Schumm, F. 2011. Fruticose Roccellaceae: an anatomical-microscopical atlas and guide with a worldwide key and further notes on some crustose Roccellaceae or similar lichens. Published by the authors and BoD [Books on Demand, available from fschumm@online.de], The Netherlands.

Brakni, R., Ahmed, M. A., Burger, P., Schwing, A., Michel, G., Pomares, C., Hasseine, L., Boyer, L., Fernandez, X., Landreau, A. \& Michel, T. 2018. 'UHPLC-HRMS/MS based profiling of Algerian lichens and their antimicrobial activities, Chemistry and Biodiversity 15: e1800031.

Chong, J., Soufan, O., Li, C., Caraus, I., Li, S. \& Bourque, G. et al. 2018. MetaboAnalyst 4.0: towards more transparent and integrative metabolomics analysis. Nucleic Acids Research 46, W1: 486-494.

Culberson, C. F. 1969. Chemical and Botanical Guide to Lichen Products. Uiversity of North Carolina Press, Chapel Hill. de Lamarck, J. B. \& de Candolle, A. P. 1805. Flore Française, ou descriptions succinctes de toutes les plantes qui croissent naturellement en France, 3(2). H. Agasse, Paris.

Duong, T. H., Huynh, B. L. C., Chavasiri, W., Chollet-Krugler, M., Nguyen, V. K., Nguyen, T. H. T., Hansen, P. E., Le Pogam, P., Thüs, H., Boustie, J. \& Nguyen, K. P. P. 2017. New erythritol derivatives from the fertile form of Roccella montagnei. Phytochemistry 137: 156-164

Duong, T. H. \& Bui, H. 2018. Chemical constituents of the lichen Roccella sinensis growing in Binh Thuan province. Science and Technology Development Journal - Natural Sciences 2: 63-67.

Elix, J., Naidu, R. \& Laundon, J. R. 1992. Synthesis of the lichen dibenzofuran pannaric acid 2-methyl ester and its isomer 3-O-methylpannaric acid. Australian Journal of Chemistry 45: 785-779.

Follman, G. \& Geyer, M. 1986. Preliminary Studies towards a monograph of the lichen family Roccellaceae Chev. V II. Secondary products and relationships of the genera Combea de Not. and Schizopelte T. M. Fries. Zeitschrift für Naturforschung 41c: 1117-1118.

Gadea, A., Le Lamer, A. C., Le Gall, S., Jonard, C., Ferron, S., Catheline, D., Ertz, D., Le Pogam, P., Boustie, J., Lohezic-Le Devehat, F. \& Charrier, M. 2018. Intrathalline Metabolite Profiles in the Lichen Argopsis friesiana Shape Gastropod Grazing Patterns. Journal of Chemical Ecology 44: 471-482.

Hivert, J., Bidault, E., Poncet, R., Fontaine, C. \& Picot, F. 2019. CONSORTIUM DE RECHERCHE «ILES EPARSES 2017-2020 $»-$ RECOFFIE : Renforcement des COnnaissances sur la Flore et la Fonge des îles Éparses - Rapport de campagne (4-30 avril 2019).

Huneck, S. 1967. Über die Inhaltsstoffe von Combea mollusca (Ach.) De Not., Roccella vicentina (Wain.) Wain., Roccella gayana Mont. und Roccella fucoides (Neck.) Wain. Zeitschrift für Naturforschung 22b: 1369-1370.

Huneck, S. 1972. 6-hydroxymethyleugenitin, ein neues chromon aus Roccella fuciformis. Phytochemistry 11: 1489-1490.

Huneck, S. \& Follmann, G. 1964. Das Vorkommen von Psoromsäure in Chiodecton stalactinum Nyl. und Roccellsäure in Dirina lutosa Zahlbr. Zeitschrift für Naturforschung 19b: 658-659.

Huneck, S. \& Follmann, G. 1967. Zur Chemie chilenischer Flechten. XVI. Über die Inhaltsstoffe einiger Roccellaceen. Zeitschrift für Naturforschung 22: 362-366.

Huneck, S. \& Follmann, G. 1968. Mitteilungen über Flechteninhaltsstoffe LV. Zur Phytochemie und Chemotaxonomie einiger Chiodectonaceen und Roccellaceen). Berichte der Deutschen Botanischen Gesellschaft. 81, H.3/4(5): 125-134.

Huneck, S. \& Yoshimura, I. 1996. Identification of lichen substances. Berlin, Heidelberg, New York: Springer Verlag.

Mallavadhani, U. V. \& Sudhakar, A. V. S. 2018. Roccellatol, a new $\beta$-orcinol based metabolite from the lichen Roccella montagnei. Natural Product Research 32: 268-274.

Marcuccio, S. \& Elix, J. A. 1983. A structural revision of picroroccellin. Tetrahedron Letters 24(13): 1445-1448.

Myers, O. D., Sumner, S. J., Li, S., Barnes, S. \& Du, X. 2017. One Step Forward for Reducing False Positive and False Negative Compound Identifications from Mass Spectrometry Metabolomics Data: New Algorithms for Constructing Extracted Ion Chromatograms and Detecting Chromatographic Peaks. Analytical Chemistry 89: 8696-8703.

Nylander, W. 1889. Lichenes insularum guineensium. Paris.

Parrot, D., T. Peresse, Hitti, E., Carrie, D., Grube, M. \& Tomasi, S. 2014. Qualitative and spatial metabolite profiling of lichens by a LC-MS approach combined with optimised extraction. Phytochemical Analysis 26: 23-33.

Pluskal, T., Castillo, S., Villar-Briones, A. \& Oresic, M. 2010. MZmine 2: Modular framework for processing, visualizing, and analyzing mass spectrometry-based molecular profile data. BMC Bioinformatics 11: 395.

Prashanth, S. R., Bharath, P., Valarmathi, R., Balaji, P., Parida, A. \& Hariharan, G. N. 2008. Species status and relationship between Roccella 
montagnei and Roccella belangeriana using DNA sequence data of nuclear ribosomal internal transcribed spacer region. Journal of Plant Biochemistry and Biotechnology 17: 91-94.

Roux, C. et al. 2017. Catalogue des lichens et champignons lichénicoles de France métropolitaine. 2e édition revue et augmentée (2017). Edit. Association française de lichénologie (A.F.L.), Fontainebleau.

Strack, D., Feige, G. B. \& Kroll, R. 1979. Screening of Aromatic Secondary Lichen Substances by High Performance Liquid Chromatography. Zeitschrift für Naturforschung 34c: 695-698.

Sweidan, A., Chollet-Krugler, M., Sauvager, A., Van de Weghe, P., Chokr, A. \& Bonnaure-Mallet, M., Tomasi, S. \& Bousarghin, L. 2017. Antibacterial activities of natural lichen compounds against Streptococcus gordonii and Porphyromonas gingivalis. Fitoterapia 121: 164-169.

Tehler, A., Dahlkild, Å., Eldenäs, P. \& Feige, G. B. 2004. The phylogeny and taxonomy of Macaronesian, European and Mediterranean Roccella (Roccellaceae, Arthoniales). Symbolae Botanicae Upsalienses 34: 432-428.

Tehler, A. \& Irestedt, M. 2007. Parallel evolution of lichen growth forms in the family Roccellaceae (Arthoniales, Ascomycota). Cladistics 23: $432-454$.

Tehler, A., Irestedt, M., Bungartz, F. \& Wedin, M. 2009a. Evolution and reproduction modes in the Roccella galapagoensis aggregate (Roccellaceae, Arthoniales). Taxon 58: 438-456.
Tehler, A., Irestedt, M., Wedin, M. \& Ertz, D. 2009b. Origin, evolution and taxonomy of American Roccella (Roccellaceae, Ascomycetes). Systematics and Biodiversity 7: 307-317.

Tehler, A., Irestedt, M., Wedin, M. \& Ertz, D. 2010. The Old World Roccella species outside Europe and Macaronesia: taxonomy, evolution and phylogeny. Systematics and Biodiversity 8: 223-246.

Tenenhaus M. 1998. La régression PLS: Théorie et pratique, Editions Technip, Paris.

Tetko, I. V., Gasteiger, J., Todeschini, R., Mauri, A., Livingstone, D., Ertl, P., Palyulin, V. A., Radchenko, E. V., Zefirov, N. S., Makarenko, A. S., Tanchuk, V. Y. \& Prokopenko, V. V. 2005. Virtual computational chemistry laboratory - design and description. Journal of Computer-Aided Molecular Design 19: 453-463. http://www. vcclab.org

Thadhani, V. M., Choudhary, M. I., Khan, S. \& Karunaratne, V. 2012. Antimicrobial and toxicological activities of some depsides and depsidones. Journal of the National Science Foundation of Sri Lanka 40: 43-48.

van den Berg, R. A., Hoefsloot, H. C. J., Westerhuis, J. A., Smilde, A. K. \& van der Werf, M. J. 2006. Centering, scaling, and transformations: improving the biological information content of metabolomics data. BMC Genomics 7: 142 . 